Supporting Information

\title{
Silica Nanoparticle Reinforced Composites as Transparent Elastomeric Damping Materials
}

Fumio Asai ${ }^{1,2^{*}}$, Takahiro Seki ${ }^{1}$, Taiki Hoshino ${ }^{3},{\text { Xiaobin } \text { Liang }^{4} \text {, Ken Nakajima }}^{4}$ and Yukikazu Takeoka $^{1 *}$

*E-mail: asai.fumio@c.mbox.nagoya-u.ac.jp; ytakeoka@chembio.nagoya-u.ac.jp

${ }^{1}$ Department of Molecular \& Macromolecular Chemistry, Nagoya University, Furo-cho, Chikusa-ku, Nagoya 464-8603, Japan ${ }^{2}$ Research \& Development Center, UNITIKA LTD. 23, Uji-Kozakura, UjiShi, Kyoto, 611-0021, Japan ${ }^{3}$ RIKEN SPring-8 Center, 1-1-1 Kouto, Sayo, Hyogo 679-51982, Japan ${ }^{4}$ Department of Chemical Science and Engineering, Tokyo Institute of Technology, Tokyo 152-8552, Japan 
Preparation of the composite elastomer

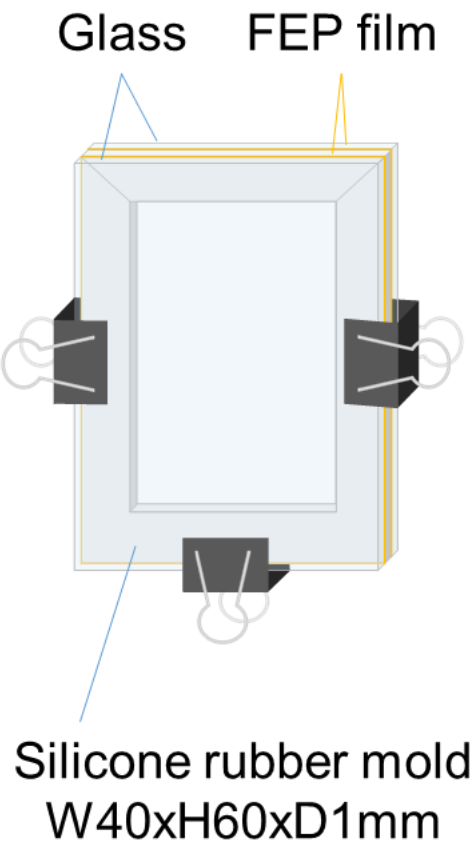

Figure S1. Schematic illustration of the mold.

Thermogravimetric analysis (TGA) and density measurements

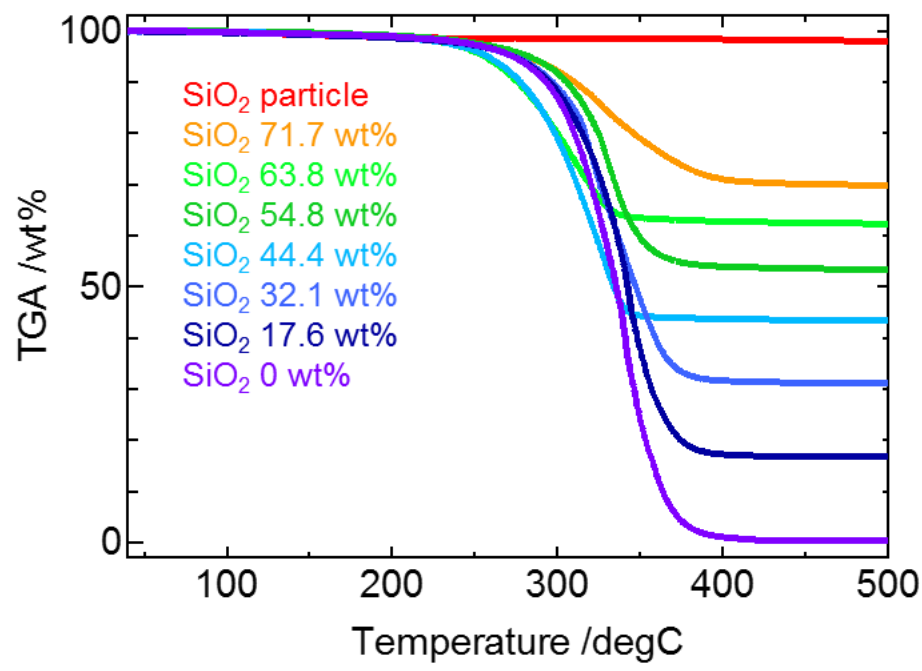

Figure S2. TGA chart of silica particles and each composite elastomer. 


\section{Transmission spectrum and specular reflection measurement}

An ultraviolet-visible near-infrared spectrophotometer (JASCO, V-670) was used as a measurement device. A light source and a detector were installed in a straight line in the vertical direction with respect to the sample, and light passing through the sample was detected. The reflection spectrum of the elastomer under specular reflection conditions was measured. The measurement was performed at $10^{\circ}$ so that the incident angle and the detection angle were equal to the vertical direction of the sample.

a

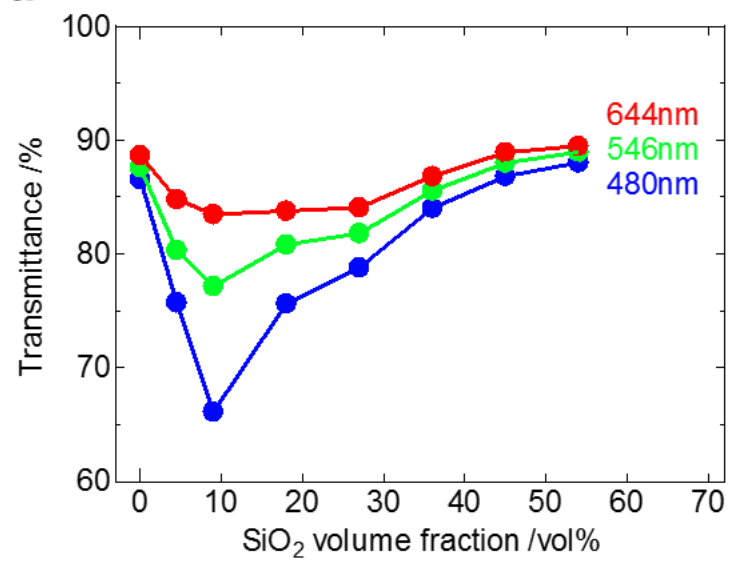

b

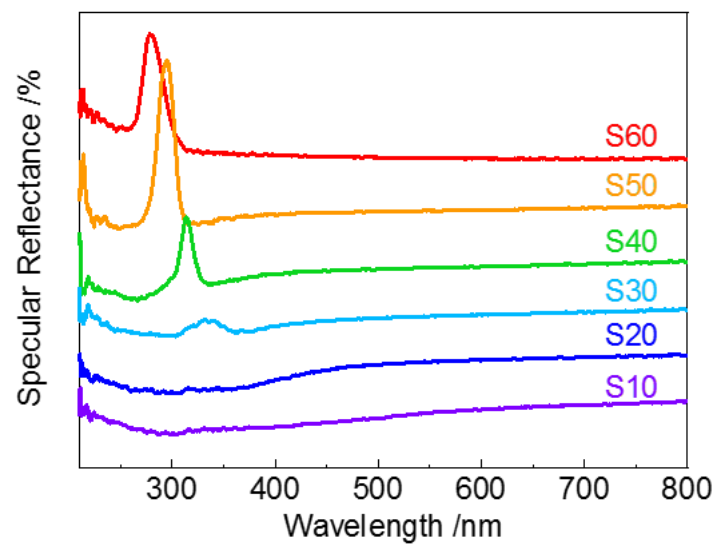

Figure S3. Optical properties of the elastomers consisting of the $\mathrm{MEO}_{2} \mathrm{MA}$ polymer and various amounts of monodispersed silica particles with an average particle size of $110 \mathrm{~nm}$. (a) Transmission spectra of the composite elastomers. (b) Specular reflectance spectra of the composite elastomers. 
Surface and cross-section SEM images

\section{Observation area}

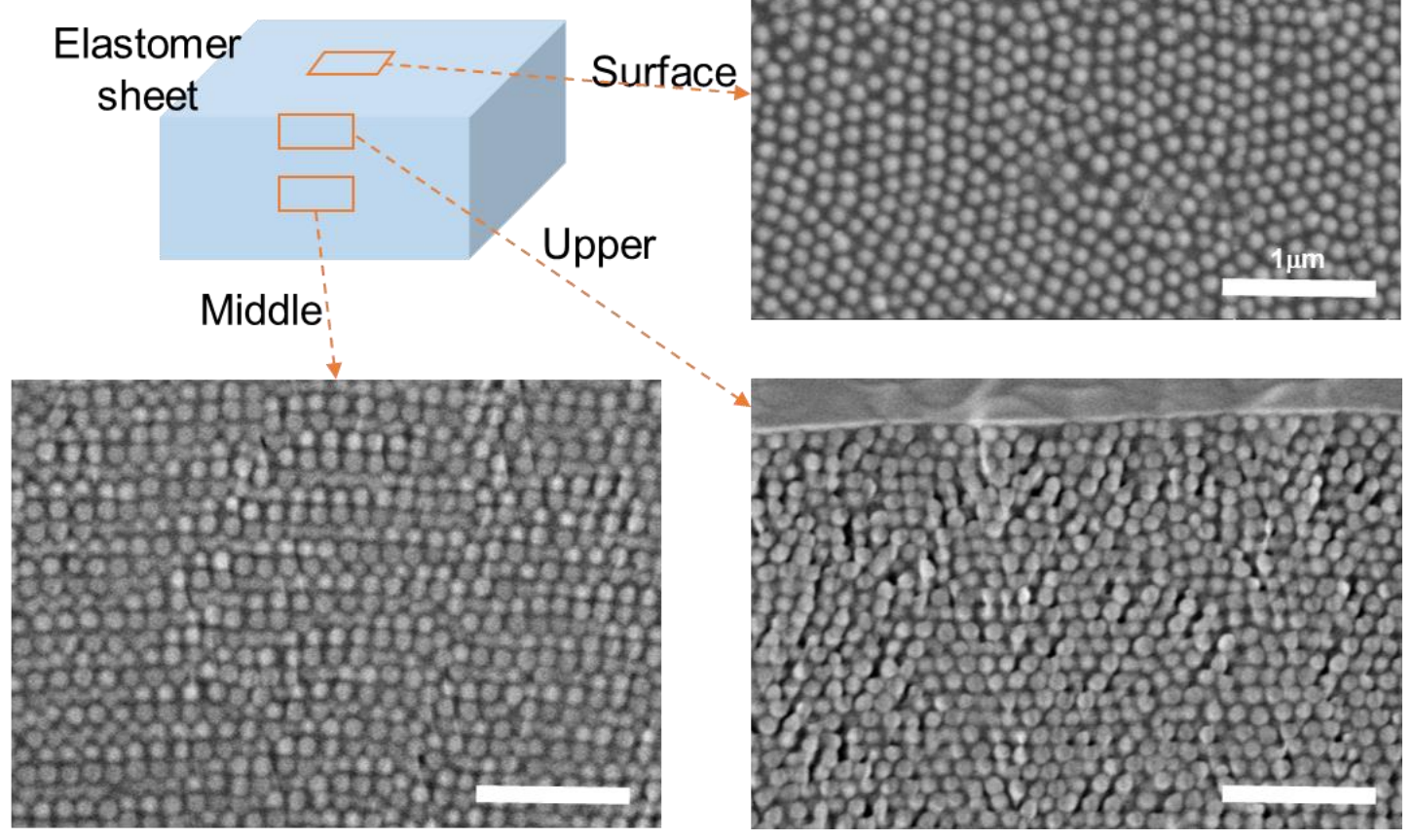

Figure S4. SEM images of the surface and cross section of S40 


\section{Examination of sonication processing energy for dispersing silica particles}

Dispersions of $\mathrm{MEO}_{2} \mathrm{MA}$ containing 36 vol\% silica particles were sonicated using an ultrasonic homogenizer (UP200St, Hielscher Ultrasonics). Dispersions were prepared by applying different processing energies, and AIBN $(0.2 \mathrm{~mol} \%)$ was added to each dispersion as an initiator. The dispersions were poured into the mold with a thickness of $1 \mathrm{~mm}$, and the composite elastomers were prepared by free-radical polymerization at $70{ }^{\circ} \mathrm{C}$ for 15 hours. Uniaxial tensile tests were performed to verify the relationship between the processing energy and mechanical properties of the composite elastomers.

a

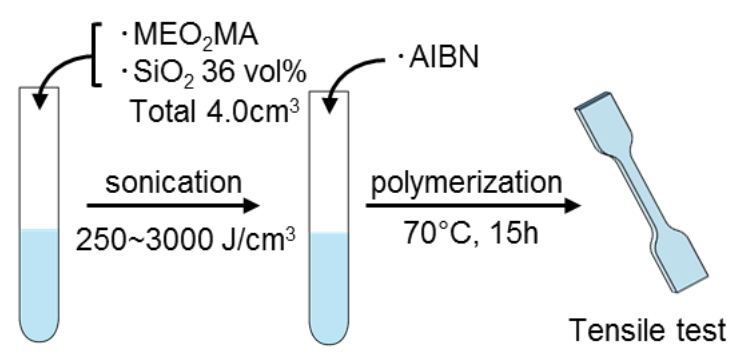

C

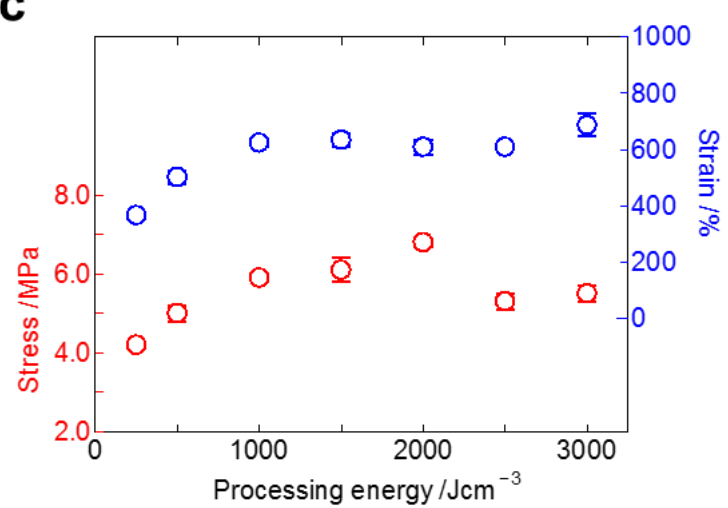

b

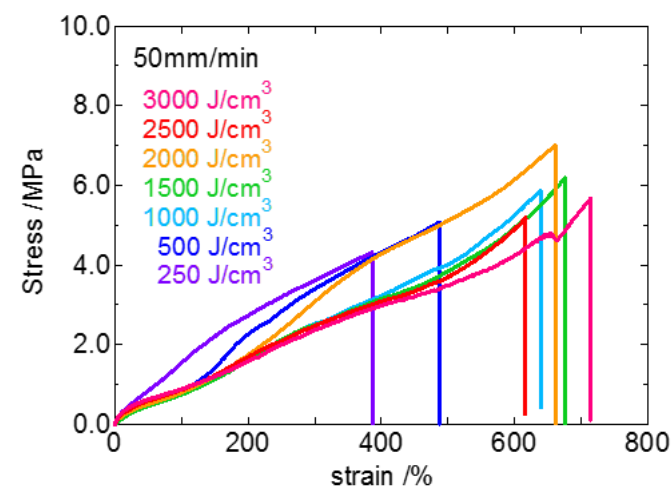

d

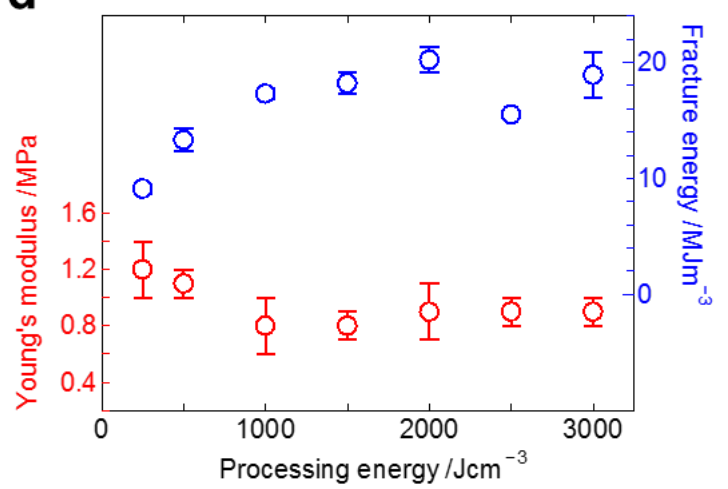

Figure S5. Examination of sonication processing energy for dispersing silica particles (a) Schematic illustration of the examination procedure. (b) Strain-stress curves of the composite elastomers to which different values of processing energy were applied. (c) Stress and strain at break at different values of processing energy. (d) Young's modulus and fracture energy at different values of processing energy. 


\section{Mechanical properties of the composite elastomers}

Table S1. The mechanical properties of the composite elastomers.

\begin{tabular}{cccccc}
\hline $\begin{array}{c}\text { Composite } \\
\text { Elastomer }\end{array}$ & $\begin{array}{c}\phi^{\mathrm{a})} \\
{[\mathrm{vol} \%]}\end{array}$ & $\begin{array}{c}E^{\mathrm{b})} \\
{[\mathrm{MPa}]}\end{array}$ & $\begin{array}{c}\sigma_{\mathrm{f}}^{\mathrm{c})} \\
{[\mathrm{MPa}]}\end{array}$ & $\begin{array}{c}\mathcal{E}_{\mathrm{f}}^{\mathrm{d})} \\
{[\%]}\end{array}$ & $\begin{array}{c}\left.\Gamma^{\mathrm{e}}\right) \\
{\left[\mathrm{MJ} \mathrm{m}^{-3}\right]}\end{array}$ \\
\hline S0 & 0 & $0.23 \pm 0.02$ & $0.5 \pm 0.0$ & $321 \pm 12$ & $0.8 \pm 0.1$ \\
S10 & 9.8 & $0.25 \pm 0.03$ & $2.3 \pm 0.2$ & $555 \pm 21$ & $4.2 \pm 0.4$ \\
S20 & 19.7 & $0.38 \pm 0.03$ & $5.0 \pm 0.4$ & $654 \pm 20$ & $12.1 \pm 1.0$ \\
S30 & 29.6 & $0.58 \pm 0.10$ & $6.4 \pm 0.3$ & $725 \pm 20$ & $18.9 \pm 1.5$ \\
S40 & 38.6 & $0.85 \pm 0.15$ & $6.8 \pm 0.1$ & $610 \pm 26$ & $20.2 \pm 1.1$ \\
S50 & 48.6 & $1.31 \pm 0.10$ & $6.0 \pm 0.2$ & $385 \pm 13$ & $13.7 \pm 0.8$ \\
S60 & 58.4 & $3.58 \pm 0.76$ & $2.5 \pm 0.1$ & $118 \pm 36$ & $2.9 \pm 1.0$ \\
\hline
\end{tabular}

${ }^{\text {a) }} \mathrm{SiO}_{2}$ fraction in the composite elastomer; ${ }^{\text {b) }}$ Young's modulus; ${ }^{\mathrm{c})}$ Stress at break; ${ }^{\mathrm{d})}$ Strain at break; ${ }^{\mathrm{e}}$ Fracture energy

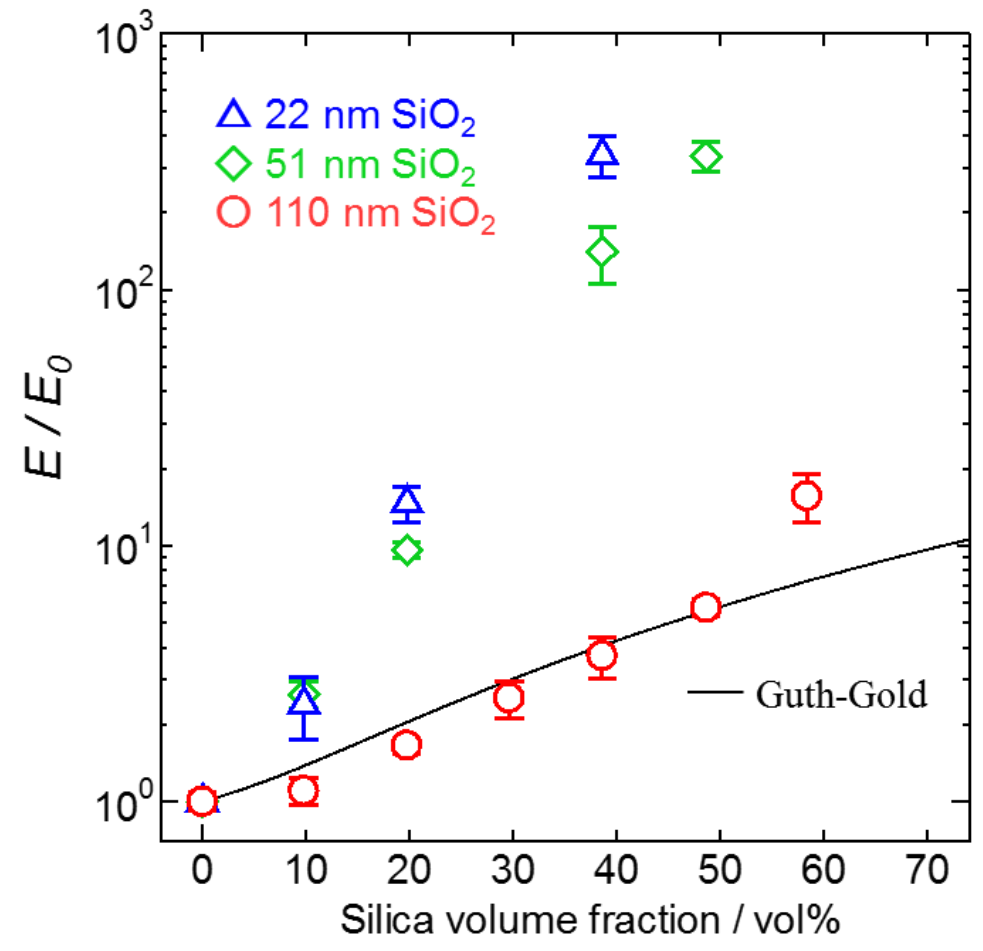

Figure S6. Young's moduli of composite elastomers containing different silica particle sizes. Symbols: $\bigcirc-110 \mathrm{~nm}$ silica particles (Silibol ${ }^{\circledR} 110$, Fuji Chemical); $\diamond-51 \mathrm{~nm}$ silica particles (Silibol ${ }^{\circledR M E 50, ~ F u j i ~ C h e m i c a l) ~} \triangle-22 \mathrm{~nm}$ silica particles (ME-ST-M, Nissan Chemical) 


\section{Poisson's ratio measurement}
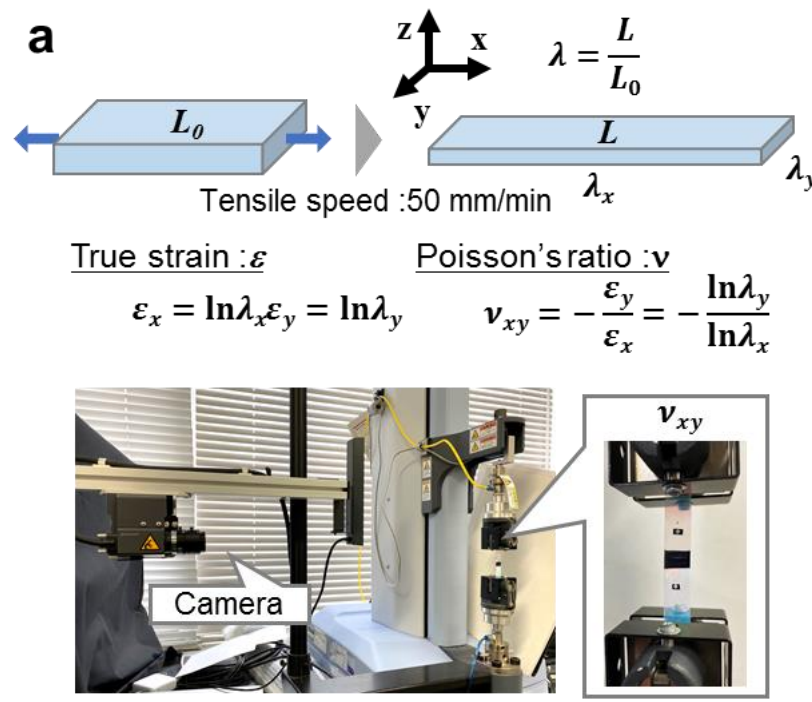

b

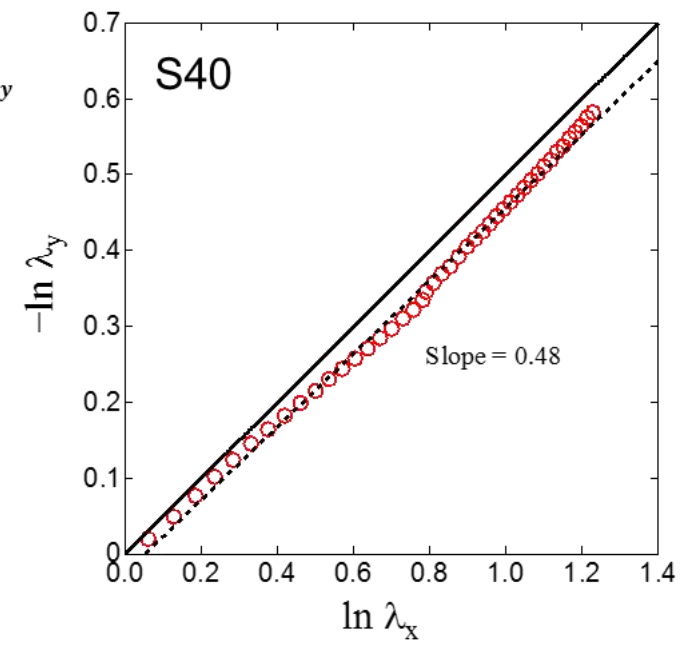

Figure S7. Poisson's ratio measurement of the composite elastomer. (a) Method for measuring Poisson's ratio for the stretching direction and the width direction $\left(v_{x y}\right)$. (b) Poisson's ratio of S40. 


\section{Hansen solubility parameter (HSP)}

To obtain the HSP of silica particles, the Hansen sphere was calculated using HSPiP software (ver. 5.3.02, developed by Dr. Hansen, Dr. Abbott and Dr. Yamamoto). Silica particles (10 mg) were added to $4 \mathrm{~mL}$ of the HSP-known solvents listed in Table S2, and the suspensions were sonicated at $1000 \mathrm{~J}$ $\mathrm{cm}^{-3}$ using an ultrasonic homogenizer (UP200St, Hielscher Ultrasonics). The particle size distribution of the silica particles in the suspensions was measured by a dynamic light scattering measuring device (Malvern, Zetasizer nano ZS), and solvents with a polydispersity index (PDI) $\leq 0.07$ were classified as good and the others as poor.

Table S2. Good and bad solvents for silica particles in the determination of HSP

\begin{tabular}{|c|c|c|c|c|c|c|}
\hline Solvent & $\begin{array}{c}\delta_{\mathrm{D}} \\
{\left[(\mathrm{MPa})^{1 / 2}\right]}\end{array}$ & $\begin{array}{c}\delta_{\mathrm{P}} \\
{\left[(\mathrm{MPa})^{1 / 2}\right]}\end{array}$ & $\begin{array}{c}\delta_{\mathrm{H}} \\
{\left[(\mathrm{MPa})^{1 / 2}\right]}\end{array}$ & $\begin{array}{l}\text { Z-Ave }{ }^{a)} \\
{[\mathrm{nm}]}\end{array}$ & $\mathrm{PDI}^{\mathrm{b})}$ & Dispersibility ${ }^{\mathrm{c}}$ \\
\hline Ethyl acetate & 15.8 & 5.3 & 7.2 & 163.5 & 0.01 & Good \\
\hline Ethanol & 15.8 & 8.8 & 19.4 & 136.2 & 0.02 & Good \\
\hline 2-Butanone (MEK) & 16.0 & 9.0 & 5.1 & 151.5 & 0.03 & Good \\
\hline Acetone & 15.5 & 10.4 & 7.0 & 162.5 & 0.05 & Good \\
\hline Methanol & 14.7 & 12.3 & 22.3 & 133.7 & 0.07 & Good \\
\hline Acetonitrile & 15.3 & 18.0 & 6.1 & 148.0 & 0.07 & Good \\
\hline$N, N$-Dimethylformamide & 17.4 & 13.7 & 11.3 & 152.0 & 0.07 & Good \\
\hline Benzyl alcohol & 18.4 & 6.3 & 13.7 & 128.1 & 0.09 & Poor \\
\hline Dimethyl sulfoxide & 18.4 & 16.4 & 10.2 & 144.0 & 0.14 & Poor \\
\hline 1,4-Dioxane & 17.5 & 1.8 & 9.0 & 165.2 & 0.18 & Poor \\
\hline Salicylaldehyde & 19.0 & 10.5 & 12.0 & 112.2 & 0.18 & Poor \\
\hline g-Butyrolactone & 18.0 & 16.6 & 7.4 & 147.6 & 0.18 & Poor \\
\hline o-Dichlorobenzene & 19.2 & 6.3 & 3.3 & 170.6 & 0.25 & Poor \\
\hline$N$-Methyl-2-pyrrolidone & 18.0 & 12.3 & 7.2 & 243.2 & 0.25 & Poor \\
\hline Formamide & 17.2 & 26.2 & 19.0 & 148.6 & 0.28 & Poor \\
\hline Cyclohexane & 16.8 & 0.0 & 0.2 & 306.7 & 0.33 & Poor \\
\hline Tetrahydrofuran & 16.8 & 5.7 & 8.0 & 173.5 & 0.35 & Poor \\
\hline Pyridine & 17.9 & 6.5 & 7.4 & 164.3 & 0.60 & Poor \\
\hline Trichloro methane & 17.8 & 3.1 & 5.7 & 2078.0 & 0.73 & Poor \\
\hline Toluene & 18.0 & 1.4 & 2.0 & 3301.0 & 1.00 & Poor \\
\hline
\end{tabular}

${ }^{\text {a) }}$ Z-Average ${ }^{\text {b) }}$ Polydispersity index ${ }^{\text {c) }}$ Solvents with PDI $\leq 0.07$ were classified as good, and other solvents were classified as poor. 
Uniaxial tensile test of the PMEA-silica composite elastomer

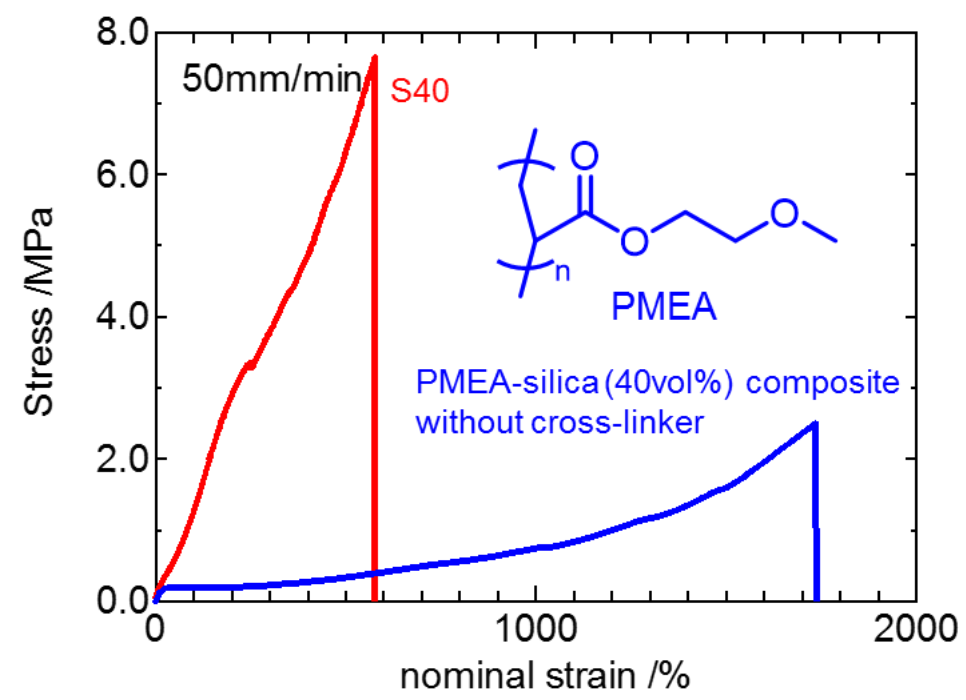

Figure S8 Stress-strain curves of S40 and the PMEA-silica composite elastomer without cross-linker.

\section{Uniaxial cyclic tensile test}

a

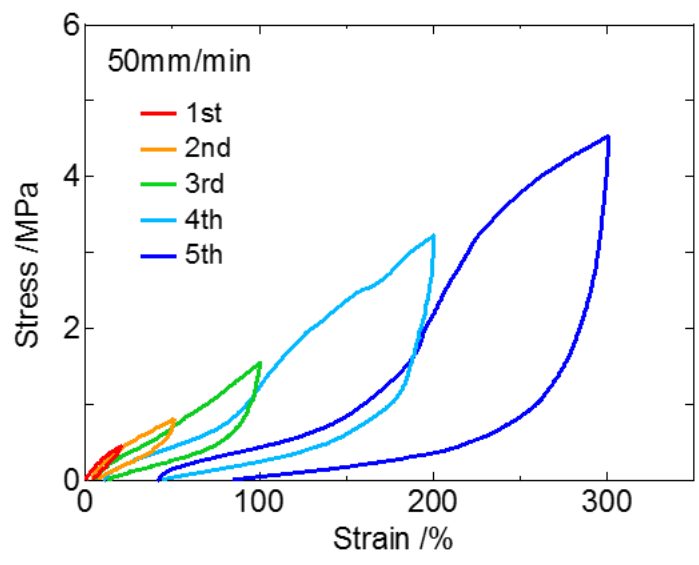

b

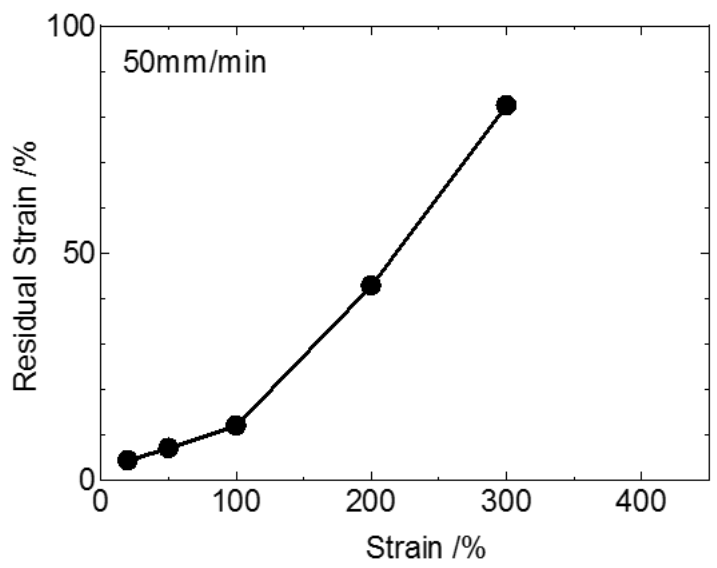

Figure S9 Hysteresis property of S40. The composite elastomer was deformed to a predetermined strain and then recovered until the stress reached zero. A series of cycles at each predetermined strain $(20,50,100,200$ and $300 \%$ at $50 \mathrm{~mm} / \mathrm{min})$ was performed sequentially, and the results were measured up to when the specimens broke. (a) Stress-strain curve of S40 from the hysteresis measurement. (b) Dependence of the residual strain on the predetermined strain. 


\section{Vibration damping loss factor measurement}

a

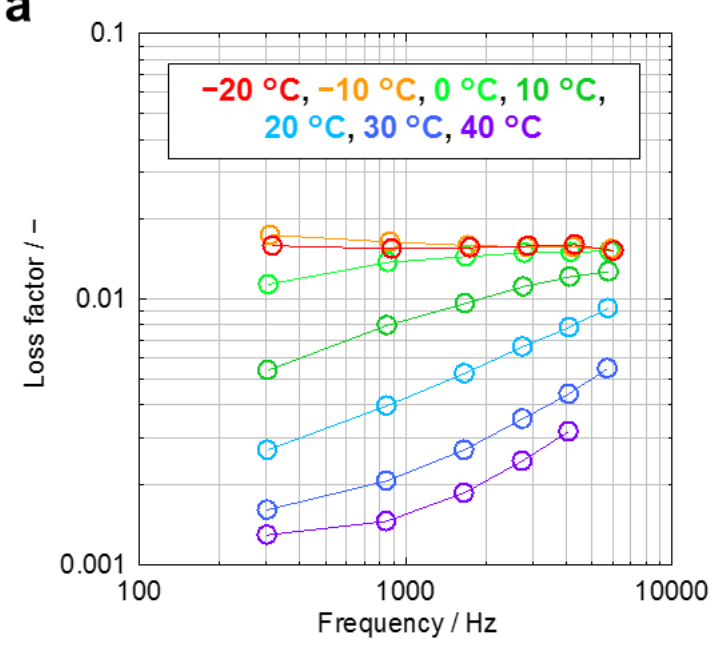

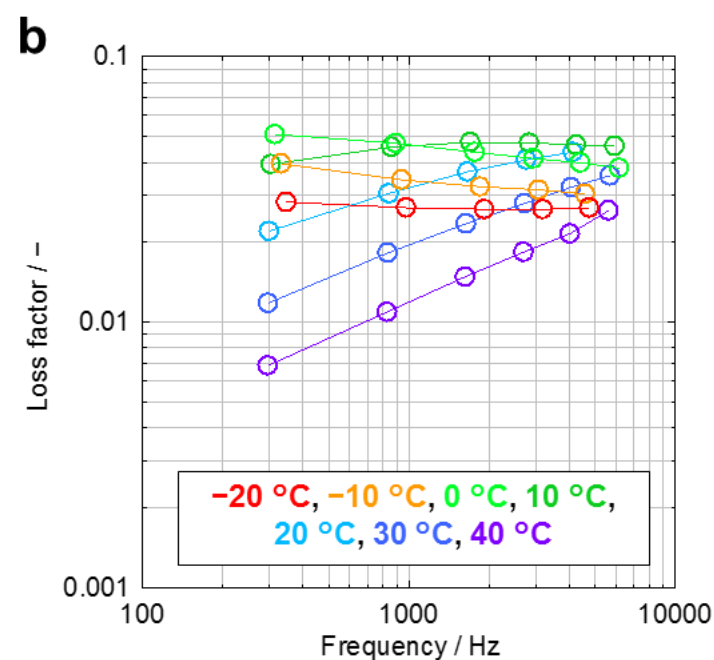

Figure S10. The loss factor of the unconstrained composite beam with the composite elastomer. (a) The loss factor of the unconstrained composite beam with S0. (b) The loss factor of the unconstrained composite beam with S40. 


\section{Dynamic mechanical analysis}

Dynamic mechanical analysis (DMA) was conducted on an RSA-G2 solid analyzer (TA instruments) in the rectangular tension geometry. Rectangular samples of $1 \mathrm{~mm} \times 5 \mathrm{~mm}$ cross section and approximately $35 \mathrm{~mm}$ length were tested at $0.5 \%$ strain. Frequency sweep tests $(0.01-100 \mathrm{~Hz})$ were conducted from -20 to $60^{\circ} \mathrm{C}$. The master curve was created by shifting the result of frequency sweep tests obtained from different temperatures based on the time-temperature superposition principle.

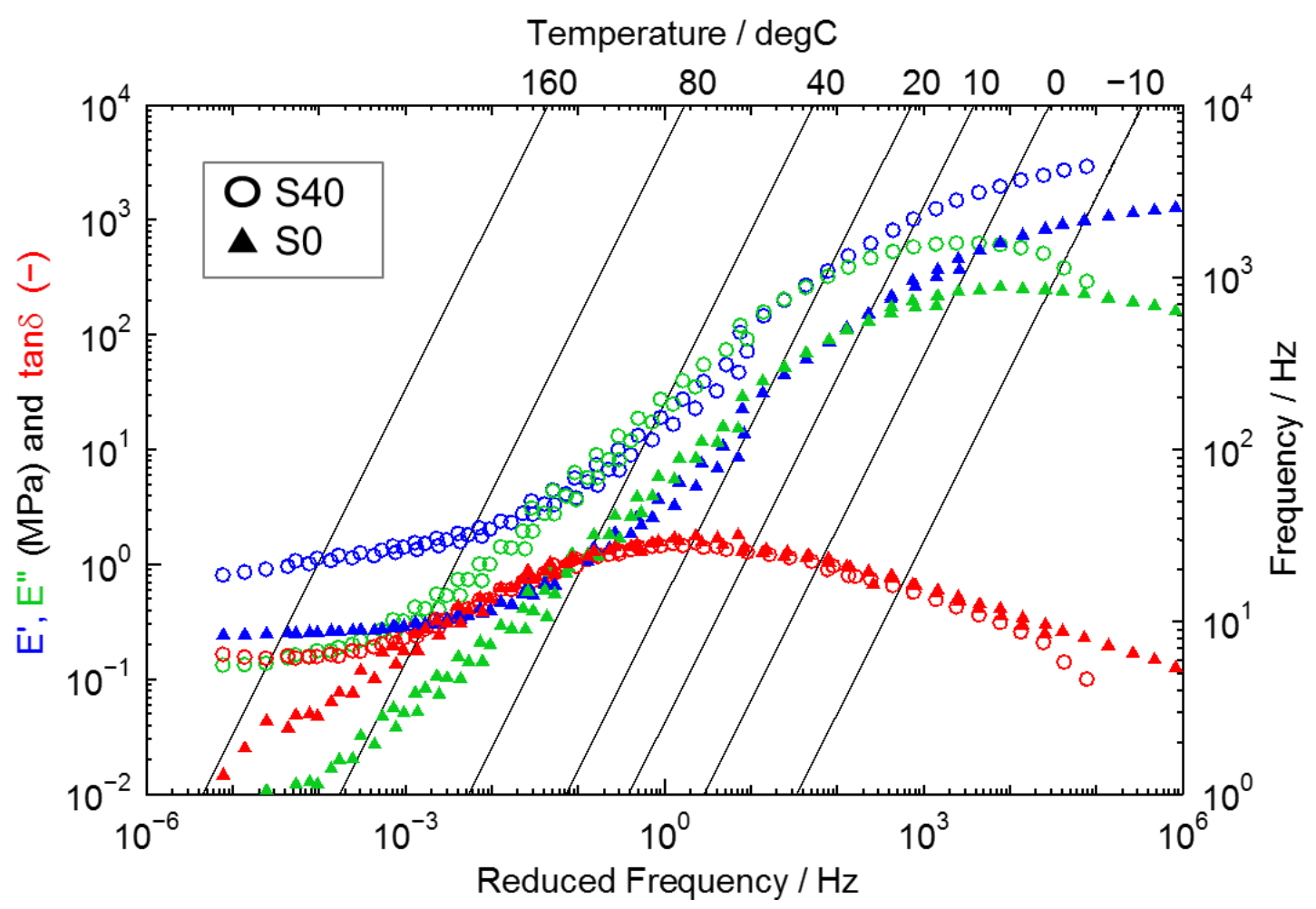

Figure S11. The mater curves of the composite elastomer. 